\title{
Extremely rapid age hardening behavior in solution treated Ti-5Al-2Fe-3Mo
}

\author{
Tomonori KUNIEDA $^{\mathrm{a}^{*}}$, Hideki FUJII ${ }^{\mathrm{b}}$ and Kazuhiro TAKAHASHI ${ }^{\mathrm{a}}$ \\ a Nippon Steel Corporation, 20-1 Shintomi, Futtsu, Chiba, 293-8510, Japan.
}

b Toho Titanium Co., LTD.

* kunieda.xx8.tomonori@jp.nipponsteel.com

\begin{abstract}
$\underline{\text { Abstract }}$
To grasp age hardening and phase transformation behaviors in a $\beta$ rich $\alpha+\beta$ type titanium alloy, Ti-5Al-2Fe-3Mo, during aging at $300-500^{\circ} \mathrm{C}$ after the solution treatment at high $\alpha+\beta$ temperature. Vickers hardness and microstructure changes during aging were closely investigated using XDR and TEM/EDS. Vickers hardness rapidly increased with increasing holding time and reached about $440 \mathrm{HV}$ by aging at $450^{\circ} \mathrm{C}$ for only $5 \mathrm{~min}$. It further increased to $510 \mathrm{HV}$ in $8 \mathrm{~h}$ of aging time. The initial stage of age hardening is extremely fast compared to that in other conventional $\alpha+\beta$ and $\beta$ type titanium alloys. After aging for only 5min, extremely fine acicular products of about 2 to $10 \mathrm{~nm}$ in width were formed in the transformed $\beta$ phase. TEM/EDS analysis revealed that all substitutional alloying elements, $\mathrm{Al}, \mathrm{Fe}$ and $\mathrm{Mo}$, homogeneously distributed after the aging, indicating that the transformation is diffusionless as far as substitutional elements are concerned just like martensite transformation although it has time dependency. To explain the mechanism of this unique phase transformation having features of isothermal martensite transformation, we propose bainitic transformation where interstitials such as $\mathrm{O}$ diffuse without conspicuous diffusion of substitutional elements.
\end{abstract}

\section{Introduction}

Ti-5Al-2Fe-3Mo is a $\beta$ rich $\alpha+\beta$ type titanium alloy and has been used for automotive engine parts such as intake valves by making use of its excellent properties such as high strength, high fatigue strength and good hot workability ${ }^{[1]}$.

Figure 1 is a schematic illustration of the phase diagram of titanium alloys, in which a horizontal axis is concentration of the $\beta$ phase stabilizing elements ${ }^{[1,2]}$. Ti-5Al-2Fe-3Mo contains total 5 mass $\%$ of the $\beta$ stabilizing elements and has higher $\beta$ stability than Ti-6Al-4 $\mathrm{V}^{[2]}$. Just like other conventional near $\beta$ type alloys, a large amount of the $\beta$ phase can be retained at room temperature by rapid cooling from the high $\alpha+\beta$ temperature region since the $\beta$ phase is more stable in the $\alpha+\beta$ two phase region as shown in Figure 1. Therefore, mechanical properties can be changed by solution treatment at high temperatures in the $\alpha+\beta$ region followed by rapid cooling. For instance, specimens solution treated at $900-930^{\circ} \mathrm{C}$, which is just below the $\beta$ transus (around $955^{\circ} \mathrm{C}$ ), followed by water quenching show extremely low $0.2 \%$ proof stress, quite high tensile strength over $1250 \mathrm{MPa}$, and low Young's modulus around $80 \mathrm{GPa}$, equivalent to $\beta$ titanium alloys ${ }^{[2]}$.

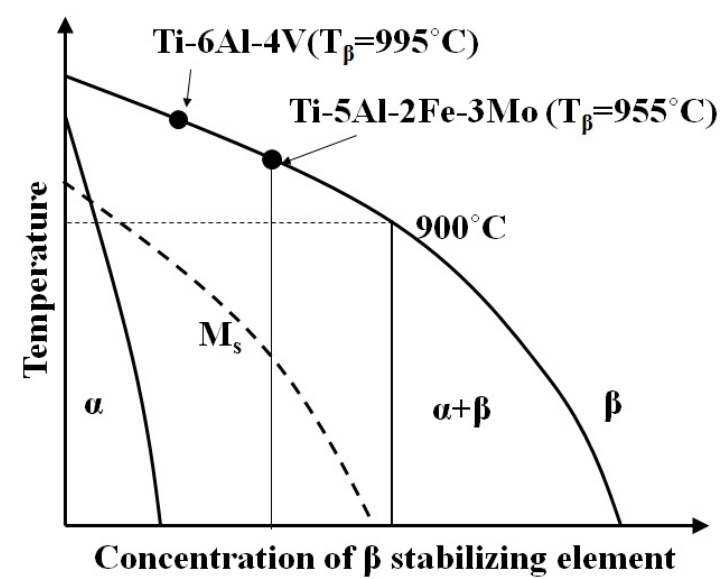

Figure 1 Schematic illustration of the phase diagram of titanium alloys ${ }^{[2]}$

(C) The Authors, published by EDP Sciences. This is an open access article distributed under the terms of the Creative Commons Attribution License 4.0 (http://creativecommons.org/licenses/by/4.0/). 
In the alloys classified into this alloy type, aging is often conducted to obtain higher strength together with balanced ductility and fracture toughness after solution treatment at high $\alpha+\beta$ temperature region. It is expected that higher strength is obtained by solution treatment and aging also in Ti-5Al-2Fe-3Mo and may widen the application range. From this point of view, age hardening and phase transformation behaviors during aging at $300-500^{\circ} \mathrm{C}$ after the solution treatment at high $\alpha+\beta$ temperature were closely investigated.

\section{Experimental procedure}

Chemical composition of a material used in this study is listed in Table 1 . The $\beta$ transus is approximately $955^{\circ} \mathrm{C}^{[1]}$. A $200 \mathrm{~kg}$ ingot was prepared by vacuum arc double remelting and the ingot was hot-forged to round bars of $100 \mathrm{~mm}$ in diameter. They were hot-rolled to round bars of $13 \mathrm{~mm}$ in diameter. Solution treatment was carried out at $900^{\circ} \mathrm{C}$ for $1 \mathrm{~h}$ followed by water quenching to room temperature. After solution treatment, the specimens were cut into $1 \mathrm{~mm}$-thick plates. The aging was conducted at 350 and $450^{\circ} \mathrm{C}$ for $5 \mathrm{~min}$ to $8 \mathrm{~h}$ followed by air cooling.

Table 1 Chemical composition of a material used(mass $\%)$

\begin{tabular}{cccccccc}
\hline Al & Fe & Mo & O & N & C & H & Ti \\
\hline 5.1 & 1.9 & 3.1 & 0.18 & 0.003 & 0.002 & 0.0049 & Bal. \\
\hline
\end{tabular}

Vickers hardness measurements (49N load) and microstructure investigations were conducted for both as solution treated specimen and subsequently aged ones. For the microstructure investigations, optical microscopy, transmission electron microscopy (TEM) and X-ray diffraction (XRD) using $\mathrm{CuK}_{\alpha}$ radiation were used. Thin foil samples for TEM observations were prepared by electro-polishing in a solution of 90 perchloric acid +525 butanol +900 methanol at around $-25^{\circ} \mathrm{C}$.

\section{Result}

Figure 2 shows the Vickers hardness change during aging at at 350 and $450^{\circ} \mathrm{C}$ in the specimens solution treated at $900^{\circ} \mathrm{C}$ followed by water quenching ${ }^{[3-5]}$. Vickers hardness in the solution treated specimen was about $340 \mathrm{HV}$. It rapidly increased with increasing holding time and reached about $440 \mathrm{HV}$ after aged at $450^{\circ} \mathrm{C}$ for only $5 \mathrm{~min}$. It further increased to $510 \mathrm{HV}$ in $8 \mathrm{~h}$ of aging time. The initial stage of age hardening is extremely fast compared to that in other conventional $\alpha+\beta$ and $\beta$ type titanium alloys, in which at least several hours are needed for hardening. Furthermore, even at $350^{\circ} \mathrm{C}$, it showed clear age hardening in only $5 \mathrm{~min}$ although it was slower than $450^{\circ} \mathrm{C}$. It indicates that the age hardening had both time and temperature dependence.

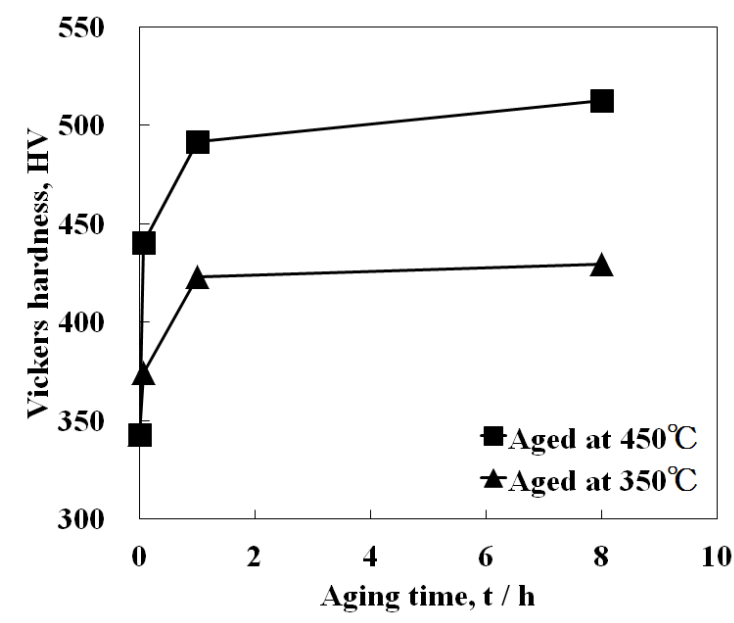


Figure 2 Age hardening behaviors during aging at 350 and $450^{\circ} \mathrm{C}$ in $\mathrm{Ti}-5 \mathrm{Al}-2 \mathrm{Fe}-3 \mathrm{Mo}$ solution treated at $900^{\circ} \mathrm{C}$ followed by water quenching

Figure 3 shows the X-ray diffraction pattern of the specimens solution treated at $900^{\circ} \mathrm{C}$ followed by water quenching and plus aged at $450^{\circ} \mathrm{C}$ for $5 \mathrm{~min}$ and $1 \mathrm{~h}$, and figure 4 shows a TEM micrograph of the specimen solution treated at $900^{\circ} \mathrm{C}$ followed by water quenching, plus aged at $450^{\circ} \mathrm{C}$. The transformed $\beta$ phase was the retained $\beta$ phase after solution treatment at $900^{\circ} \mathrm{C}$ followed by water quenching ${ }^{[2]}$. Meanwhile, the peaks of the $\beta$ phase was reduced after aging at $450^{\circ} \mathrm{C}$ for $5 \mathrm{~min}$ by XRD and extremely fine acicular products of about 2 to $10 \mathrm{~nm}$ in width were observed in the transformed $\beta$ phase by TEM. The fine acicular transformation products had the hep structure fulfilling the Burgers orientation relationship with the parent $\beta$ phase. Furthermore, by TEM/EDS analysis, it was confirmed that Ti and substitutional alloying elements such as Fe, Mo and Al homogeneously distributed after aging. It indicates that the transformation from the $\beta$ to the hcp phase is diffusionless as far as substitutional elements are concerned just like martensite transformation although it has time and temperature dependency.

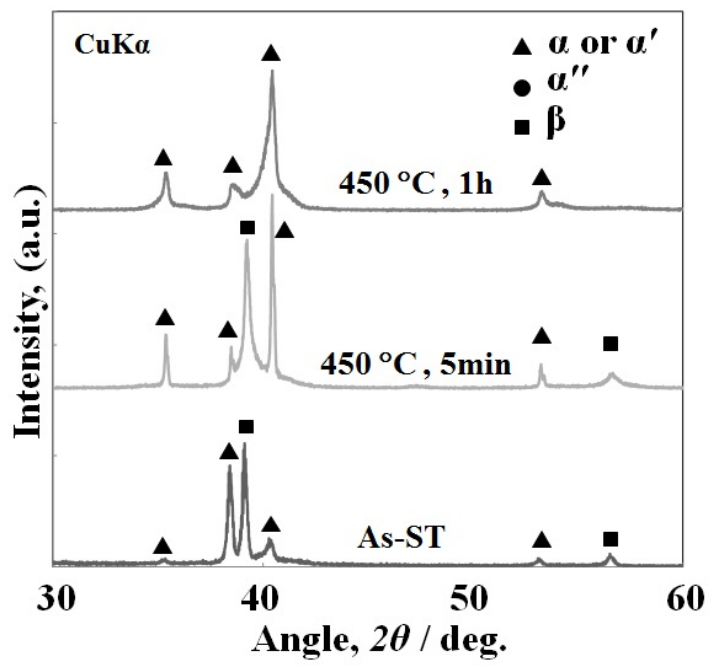

Figure $3 \mathrm{X}$-ray diffraction patterns for Ti5-2Fe-3Mo solution treated at $900^{\circ} \mathrm{C}$ and aged at $450^{\circ} \mathrm{C}$ for $5 \mathrm{~min}$ and $1 \mathrm{~h}^{[3]}$

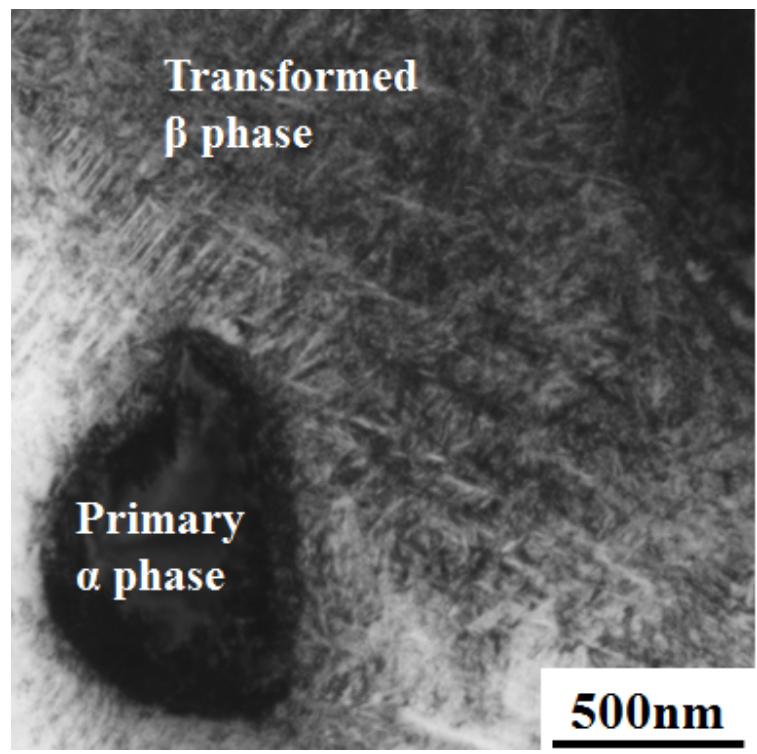

Figure 4 TEM micrograph after aging at $450^{\circ} \mathrm{C}$ for $5 \mathrm{~min}$ in Ti-5Al-2Fe-3Mo solution treated at $900^{\circ} \mathrm{C}$ followed by water quenching. 
After aged at $450^{\circ} \mathrm{C}$ for $1 \mathrm{~h}$, the peaks corresponding to the $\beta$ phase diminished and only the hcp peaks were recognized by XRD. In addition, the width at half maximum height of diffraction peaks corresponding to the hcp phase was slightly broad compared to that for the as solution treated one. Meanwhile, it was confirmed that the microstructure was not changed from that for the specimen aged for $5 \mathrm{~min}$ by TEM observation. These results indicate that the retained $\beta$ phase was perfectly transformed to the hcp phase although several percent of the $\beta$ phase was stably existing in equilibrium at room temperature.

\section{Discussion}

In general, aging time is considerably long to obtain high strength and stable properties including acceptable level of ductility and toughness in the $\alpha+\beta$ and the $\beta$ type titanium alloys as described before in the "Results". For example, at least $1 \mathrm{~h}$ and generally more than $8 \mathrm{~h}$ are needed at around $500^{\circ} \mathrm{C}$ in a $\beta$ type titanium alloy, Ti-15V-3Cr-3Sn-3Al ${ }^{[6]}$. The mechanism of age hardening in the alloy is precipitation of the $\omega$ and the $\alpha$ phases in the retained $\beta$ phase during aging. Meanwhile, the age hardening behavior in Ti-5Al-2Fe-3Mo is extremely fast compared to that in the conventional $\alpha+\beta$ and $\beta$ type titanium alloys. The age hardening was clear for only $5 \mathrm{~min}$ at $450^{\circ} \mathrm{C}$. Furthermore, the fine acicular products were formed in the retained $\beta$ phase during aging at $450^{\circ} \mathrm{C}$ although $\mathrm{Ti}$ and substitutional elements such as $\mathrm{Al}$, Fe and Mo homogeneously distributed according to the TEM/EDS analysis. It indicates that the transformation is diffusionless as far as substitutional elements are concerned just like martensite transformation, as pointed out in the "Results". Meanwhile, the aging hardening behavior showed dependence of temperature and time, indicating that diffusion of some element influences this unusual phase transformation. It is considered that the interstitial element oxygen, which can diffuse even in this temperature range, strongly affects the phase transformation. A possible mechanism which can explain above mentioned phenomena is introduced below.

The transformed $\beta$ phase in which oxygen is excessively contained as a solid solution is formed by solution treatment at $\alpha+\beta$ high temperature region followed by water quenching. During aging at around $450{ }^{\circ} \mathrm{C}$ after solution treatment, low oxygen concentration areas are formed in the $\beta$ phase, in which solid solution hardening effect by oxygen is lowered and the resistance hindering the martensite transformation is also lowered. Then the $\beta$ phase is transformed to the $\alpha^{\prime}$ hcp martensite phase via the $\alpha^{\prime \prime}$ orthorhombic martensite phase. With this mechanism, time and temperature dependence of the transformation and the features of isothermal martensite transformation can be explained. We propose that the transformation is bainitic transformation where only interstitials such as oxygen diffuse without conspicuous diffusion of substitutional elements.

\section{Summary}

In $\beta$ rich $\alpha+\beta$ type titanium alloy, Ti-5Al-2Fe-3Mo, extremely fast age hardening compared to that in conventional $\alpha+\beta$ and $\beta$ type titanium alloys was occurred during aging at $450^{\circ} \mathrm{C}$ after solution treatment at $\alpha+\beta$ high temperature region followed by water quenching. After aging at $450^{\circ} \mathrm{C}$ for only $5 \mathrm{~min}$, extremely fine acicular products of about 2 to $10 \mathrm{~nm}$ in width were formed in the transformed $\beta$ phase. TEM/EDS analysis revealed that all substitutional alloying elements homogeneously distributed after the aging, indicating that the transformation is diffusionless as far as substitutional elements are concerned just like martensite transformation although it has time dependency. To explain the mechanism of this unique phase transformation having features of isothermal martensite, we propose bainitic transformation where interstitials such as O diffuse without conspicuous diffusion of substitutional elements.

\section{Reference}

[1] K. Mori, K. Takahashi and H. Fujii:Titanium Japan, 55 (2007), 34. (in Japanese)

[2] T. Kunieda, K. Mori, K. Takahashi and H. Fujii: NSSMC Tech. Rep., 106, (2014), 47.

[3] T Kunieda, H. Fujii K. Takahashi K. Wada and Y. Takemoto:CAMP-ISIJ, 26, (2013), 442. (in Japanese)

[4] T Kunieda, H. Fujii K. Takahashi K. Wada and Y. Takemoto:CAMP-ISIJ, 26, (2013), 443. (in Japanese)

[5] T Kunieda, H. Fujii K. Takahashi and Y. Takemoto: CAMP-ISIJ, 26 (2013), 1065. (in Japanese)

[6] H. Fujii and H. G. Suzuki ; Mat. Trans. JIM, 34(1993), 373. 